\title{
COMMENTARIES
}

\section{Simple Control}

\author{
Nachshon Meiran \\ Department of Psychology and Zlotowski Center for Neuroscience, Ben-Gurion University of the Negev, Beer-Sheva, IL \\ nmeiran@bgu.ac.il
}

Keywords: Attention; Executive functions; Cognitive Control

Schmidt, Liefooghe and De Houwer (2020, henceforth, SLD) present an impressive theoretical work, which suggests a novel perspective on task-switching behavior and also shows its unique contribution relative to other models. In a nutshell, SLD show that switching-cost, believed to be an empirical marker of cognitive control, can be explained in terms of simple episodic binding.

Models serve for model-based estimation of latent variables (e.g., Signal Detection Theory, McMillan, 2004, enabling the estimation of sensitivity and bias) and as proofs of concept (e.g., SLD's model, showing that episodic binding can explain switching cost), thereby clarifying the necessary assumptions in a scientific explanation. I address these two aspects in turn.

Estimation of latent variables is widespread in cognitive psychology, with subtraction (also employed to compute switch cost) being probably the most widely used model. As usual, the estimate (e.g., switch cost) is valid as long as the underlying model is approximately valid. To appreciate this point, consider a hypothetical model assuming that task-switch trials entail reconfiguration, a switch-unique proactive processing stage that precedes response selection. Under this model, switch-cost $=R T_{\text {switch }}-R T_{\text {non-switch }}$ provides an estimate for the duration of the (latent) reconfiguration processing stage. We however already know this model to be inaccurate because (a) residual switch cost, i.e. switch cost observed after ample advance task-preparation, is often observed, suggesting the involvement of additional processes beyond reconfiguration; and (b), the slope describing the reduction in switch cost as a function of task preparation time is far shallower than -1 (see Pashler, 1994). This finding suggests that reconfiguration, at minimum, is very slow and inefficient when performed ahead of the imperative stimulus, a fact that seems to argue against the proactivity hypothesis in general. SLD provide an alternative account of switch costs but seem to also suggest that switch costs do not represent cognitive control but represent what they describe as simpler memory mechanisms. I doubt this conclusion and will suggest one challenging fact: the increased switch cost observed in attention deficits. This finding that has been replicated several times, including a related finding of "normalization" of switch costs under methylphenidate treatment (Kramer, Cepeda, \& Cepeda, 2001; Luna-Rodriguez, Wendt, Kerner auch Koerner, Gawrilow, \& Jacobsen, 2018; Rauch, Gold, \& Schmitt, 2012). Given how attention deficits are defined by the DSM (American Psychiatric Association, 2013), it is difficult to attribute the increased switch cost and its "normalization" to features that are completely unrelated to cognitive control. A possible solution is that switch cost is related to reactive control rather than proactive control (Braver, Reynolds, \& Donaldson, 2003), implying that attention deficits reflect a difficulty in reactive control (Grane et al., 2016). SLD's model suggests another hypothesis regarding an indirect link. According to it, people who are characterized by attention deficits compensate for it by reliance on episodic memory, which results in increased switching costs.

I now turn to the use of models as a proof of concept. An important advantage of this use is the requirement to specify necessary assumptions and clarify their explanatory contribution. As acknowledged by SLD, their model had to incorporate control-related features including serial processing, abstract task representations, instructions, and the recall of instructions after errors (SLD, Appendix B). In Duncan's (2010) "general demand network", serial processing requires setting the processing sequence and monitoring its progress. In Logan and Gordon's (2001) ECTVA model, the function of serial processing to reduce crosstalk and errors, and accordingly, increased control demands are accompanied by a shift to serial processing (Luria \& Meiran, 2005). Arguably, as a result of insufficiently abstract task representations, toddlers fail task 
switching, and "get stuck" on a single task (Zelazo, 2004), and when not focusing on abstract task representations, adult participants, like pigeons (Castro \& Wasserman, 2016) and monkeys (Avdagic, Jensen, Altschul, \& Terrace, 2014; Stoet \& Snyder, 2003) perform the task switching task as if it were a single task and do not show switch costs (Dreisbach, Goschke, \& Haider, 2006, 2007). Moreover, abstract task representations, like serial processing, reduce crosstalk and interference (Dreisbach, 2012). Interestingly, the evolution of the primate cortex resulted in us having association cortices that are remote from primary sensory systems, enabling representational abstractness and behavioral flexibility (Kaas \& Herculano-Houzel, 2017). Along a similar line, the posterior (close to primary sensory)-to-anterior (remote from primary sensory) axis in the human prefrontal cortex also reflects a representational shift from concrete to abstract (Koechlin \& Summerfield, 2007; O'Reilly, 2010). These observation suggest that instructions in a very specific (abstract) format are an essential requirement for task switching to happen and switch cost to emerge. The recall of instructions after errors may in fact underlie the control-related, and especially pronounced post-error slowing observed in the task-switching task (Regev \& Meiran, 2014). Although SLD's model suggests that task-switching involves many aspects of control, it does not suggest an involvement of the key control element of working memory. This conclusion seems to be in line with the fact that following novel instructions is impaired by working memory load (Pereg \& Meiran, 2019). However, working memory seems to be relatively minimally involved in the task-switching task, in which the same instructions are executed multiple times (e.g., Kessler \& Meiran, 2009; Rubin \& Meiran, 2005; van 't Wout, Lavric, \& Monsell, 2013).

My conclusions are that contrary to a widely held belief, "automatic" and "episodic" are not alternatives to cognitive control. For example, automatic effects may reflect side effects of control (Meiran, Liefooghe, \& De Houwer, 2017). Thus, as suggested by SLD's model, it is the joint operation of "simple" processes of episodic memory and the aforementioned control features that enable cognitive control operations to occur.

\section{Ethics and Consent}

To my knowledge, the present work does not violate any ethical standards.

\section{Acknowledgements}

I wish to thank Yoav Kessler for helpful comments.

\section{Competing Interests}

The author has no competing interests to declare.

\section{References}

American Psychiatric Association. (2013). Diagnostic and Statistical Manual of Mental Disorders (Fifth Edition). American Psychiatric Association. DOI: https://doi.org/10.1176/appi.books.9780890425596

Avdagic, E., Jensen, G., Altschul, D., \& Terrace, H. S. (2014). Rapid cognitive flexibility of rhesus macaques performing psychophysical task-switching. Animal Cognition, 17, 619-631. DOI: https://doi. org/10.1007/s 10071-013-0693-0

Braver, T. S., Reynolds, J. R., \& Donaldson, D. I. (2003). Neural mechanisms of transient and sustained cognitive control during task switching. Neuron, 39, 713-726. DOI: https://doi.org/10.1016/S08966273(03)00466-5

Castro, L., \& Wasserman, E. A. (2016). Executive control and task switching in pigeons. Cognition, 146, 121-135. DOI: https://doi.org/10.1016/j.cognition.2015.07.014

Dreisbach, G. (2012). Mechanisms of cognitive control The functional role of task rules. Current Directions in Psychological Science, 21, 227-231. DOI: https://doi.org/10.1177/0963721412449830

Dreisbach, G., Goschke, T., \& Haider, H. (2006). Implicit task sets in task switching? Journal of Experimental Psychology: Learning, Memory, and Cognition, 32, 1221-1233. DOI: https://doi.org/ 10.1037/0278-7393.32.6.1221

Dreisbach, G., Goschke, T., \& Haider, H. (2007). The role of task rules and stimulus-response mappings in the task switching paradigm. Psychological Research, 71, 383-392. DOI: https://doi.org/10.1007/ s00426-005-0041-3

Duncan, J. (2010). The multiple-demand (MD) system of the primate brain: Mental programs for intelligent behaviour. Trends in Cognitive Sciences, 14, 172-179. DOI: https://doi.org/10.1016/j.tics.2010.01.004

Grane, V. A., Brunner, J. F., Endestad, T., Aasen, I. E. S., Kropotov, J., Knight, R. T., \& Solbakk, A.-K. (2016). ERP correlates of proactive and reactive cognitive control in treatment-naïve adult ADHD. PLoS ONE, 11. DOI: https://doi.org/10.1371/journal.pone.0159833 
Kaas, J. H., \& Herculano-Houzel, S. (2017). What makes the human brain special: Key features of brain and neocortex. In I. Opris \& M. F. Casanova (Eds.), The Physics of the Mind and Brain Disorders: Integrated Neural Circuits Supporting the Emergence of Mind (pp. 3-22). Cham: Springer International Publishing. DOI: https://doi.org/10.1007/978-3-319-29674-6_1

Kessler, Y., \& Meiran, N. (2009). The reaction-time task-rule congruency effect is not affected by working memory load: Further support for the activated long-term memory hypothesis. Psychological Research, 74, 388-399. DOI: https://doi.org/10.1007/s00426-009-0261-z

Koechlin, E., \& Summerfield, C. (2007). An information theoretical approach to prefrontal executive function. Trends in Cognitive Sciences, 11, 229-235. DOI: https://doi.org/10.1016/j.tics.2007.04.005

Kramer, A., Cepeda, N., \& Cepeda, M. (2001). Methylphenidate Effects on Task-Switching Performance in Attention-Deficit/Hyperactivity Disorder. Journal of the American Academy of Child \& Adolescent Psychiatry, 40, 1277-1284. DOI: https://doi.org/10.1097/00004583-200111000-00007

Logan, G. D., \& Gordon, R. D. (2001). Executive control of visual attention in dual-task situations. Psychological Review, 108, 393-434. DOI: https://doi.org/10.1037/0033-295X.108.2.393

Luna-Rodriguez, A., Wendt, M., Kerner auch Koerner, J., Gawrilow, C., \& Jacobsen, T. (2018). Selective impairment of attentional set shifting in adults with ADHD. Behavioral and Brain Functions, 14, 18. DOI: https://doi.org/10.1186/s12993-018-0150-y

Luria, R., \& Meiran, N. (2005). Increased control demand results in serial processing: Evidence from dual-task performance. Psychological Science, 16, 833-840. DOI: https://doi.org/10.1111/j.1467-9280. 2005.01622.x

McMillan, N. A. (2004). Detection theory: A user's guide (2 edition). Mahwah, NJ: Lawrence Erlbaum. DOI: https://doi.org/10.4324/9781410611147

Meiran, N., Liefooghe, B., \& De Houwer, J. (2017). Powerful instructions: Automaticity without practice. Current Directions in Psychological Science, 26, 509-514. DOI: https://doi.org/10.1177/ 0963721417711638

O'Reilly, R. C. (2010). The What and How of prefrontal cortical organization. Trends in Neurosciences, 33, 355-361. DOI: https://doi.org/10.1016/j.tins.2010.05.002

Pashler, H. (1994). Dual-task interference in simple tasks: Data and theory. Psychological Bulletin, 116, 220-244. DOI: https://doi.org/10.1037/0033-2909.116.2.220

Pereg, M., \& Meiran, N. (2019). Rapid instructed task learning (but not automatic effects of instructions) is influenced by working memory load. PLOS ONE, 14, 1-25. DOI: https://doi.org/10.1371/journal. pone. 0217681

Rauch, W. A., Gold, A., \& Schmitt, K. (2012). To what extent are task-switching deficits in children with attention-deficit/hyperactivity disorder independent of impaired inhibition? ADHD Attention Deficit and Hyperactivity Disorders, 4, 179-187. DOI: https://doi.org/10.1007/s12402-012-0083-5

Regev, S., \& Meiran, N. (2014). Post-error slowing is influenced by cognitive control demand. Acta Psychologica, 152, 10-18. DOI: https://doi.org/10.1016/j.actpsy.2014.07.006

Rubin, O., \& Meiran, N. (2005). On the origins of the task mixing cost in the cuing task-switching paradigm. Journal of Experimental Psychology: Learning, Memory, and Cognition, 31, 1477-1491. DOI: https://doi. org/10.1037/0278-7393.31.6.1477

Schmidt, J. R., Liefooghe, B., \& De Houwer, J. (2020). An episodic model of task-switching effect: Erasing the homunculus from memory. Journal of Cognition, 3(1): 22, pp. 1-38. DOI: https://doi.org/10.5334/ joc.97

Stoet, G., \& Snyder, L. H. (2003). Executive control and task-switching in monkeys. Neuropsychologia, 41, 1357-1364. DOI: https://doi.org/10.1016/S0028-3932(03)00048-4

van't Wout, F., Lavric, A., \& Monsell, S. (2013). Are stimulus-response rules represented phonologically for task-set preparation and maintenance? Journal of Experimental Psychology: Learning, Memory, and Cognition, 39, 1538-1551. DOI: https://doi.org/10.1037/a0031672

Zelazo, P. D. (2004). The development of conscious control in childhood. Trends in Cognitive Sciences, 8 , 12-17. DOI: https://doi.org/10.1016/j.tics.2003.11.001 
How to cite this article: Meiran, N. 2020 Simple Control. Journal of Cognition, 3(1): 26, pp. 1-4. DOl: https://doi. org/10.5334/joc.107

\section{Submitted: 24 April 2020 Accepted: 18 June 2020 Published: 10 September 2020}

Copyright: ( 2020 The Author(s). This is an open-access article distributed under the terms of the Creative Commons Attribution 4.0 International License (CC-BY 4.0), which permits unrestricted use, distribution, and reproduction in any medium, provided the original author and source are credited. See http://creativecommons.org/ licenses/by/4.0\%

] $\mathbf{u}$ Journal of Cognition is a peer-reviewed open access journal published by Ubiquity 